\title{
Wnt and Notch signaling govern self-renewal and differentiation in a subset of human glioblastoma stem cells
}

\author{
Nishani Rajakulendran, ${ }^{1,12}$ Katherine J. Rowland, ${ }^{2,12}$ Hayden J. Selvadurai, ${ }^{2}$ Moloud Ahmadi, ${ }^{1}$ \\ Nicole I. Park, ${ }^{2,3}$ Sergey Naumenko, ${ }^{4,5}$ Sonam Dolma, ${ }^{2}$ Ryan J. Ward, ${ }^{2}$ Milly So, ${ }^{2}$ Lilian Lee, ${ }^{2}$ \\ Graham MacLeod, ${ }^{1}$ Clarissa Pasiliao, ${ }^{2,3}$ Caroline Brandon, ${ }^{2}$ Ian D. Clarke ${ }^{2,11}$ Michael D. Cusimano, ${ }^{4,5}$ \\ Mark Bernstein, ${ }^{6}$ Nizar Batada, ${ }^{7}$ Stephane Angers, ${ }^{1,8}$ and Peter B. Dirks ${ }^{2,3,9,10}$ \\ ${ }^{1}$ Leslie Dan Faculty of Pharmacy, Department of Pharmaceutical Sciences, University of Toronto, Toronto, Ontario M5S 3M2, \\ Canada ${ }^{2}$ Developmental and Stem Cell Biology Program, Arthur and Sonia Labatt Brain Tumour Research Centre, The Hospital for \\ Sick Children, Toronto, Ontario M5G 0A4, Canada; ${ }^{3}$ Faculty of Medicine, Department of Molecular Genetics, University of \\ Toronto, Toronto, Ontario M5G 0A4, Canada; ${ }^{4}$ Genetics and Genome Biology Program, The Hospital for Sick Children, Toronto, \\ Ontario M5G 0A4, Canada; ${ }^{5}$ St. Michael's Hospital, Toronto, Ontario M5B 1W8, Canada; ${ }^{6}$ Toronto Western Hospital, Toronto, \\ Ontario M5T 2S8, Canada; ${ }^{7}$ Institute of Genetics and Molecular Medicine, Edinburgh EH4 2XU, United Kingdom; ${ }^{8}$ Faculty of \\ Medicine, Department of Biochemistry, University of Toronto, Toronto, Ontario M5S 1A8, Canada; ${ }^{9}$ Faculty of Medicine, \\ Department of Surgery, University of Toronto, Toronto, Ontario M5S 1A8, Canada; ${ }^{10}$ Division of Neurosurgery The Hospital for \\ Sick Children, Toronto, Ontario M5G 1X8, Canada
}

Developmental signal transduction pathways act diversely, with context-dependent roles across systems and disease types. Glioblastomas (GBMs), which are the poorest prognosis primary brain cancers, strongly resemble developmental systems, but these growth processes have not been exploited therapeutically, likely in part due to the extreme cellular and genetic heterogeneity observed in these tumors. The role of Wnt/ $\beta$ catenin signaling in GBM stem cell (GSC) renewal and fate decisions remains controversial. Here, we report context-specific actions of Wnt/ $\beta$ catenin signaling in directing cellular fate specification and renewal. A subset of primary GBM-derived stem cells requires Wnt proteins for self-renewal, and this subset specifically relies on Wnt/ßcatenin signaling for enhanced tumor burden in xenograft models. In an orthotopic Wnt reporter model, Wnt ${ }^{\text {hi }}$ GBM cells (which exhibit high levels of $\beta$ catenin signaling) are a faster-cycling, highly self-renewing stem cell pool. In contrast, Wnt ${ }^{\text {lo }}$ cells (with low levels of signaling) are slower cycling and have decreased self-renewing potential. Dual inhibition of Wnt/ $\beta$ catenin and Notch signaling in GSCs that express high levels of the proneural transcription factor ASCL1 leads to robust neuronal differentiation and inhibits clonogenic potential. Our work identifies new contexts for Wnt modulation for targeting stem cell differentiation and self-renewal in GBM heterogeneity, which deserve further exploration therapeutically.

[Keywords: Ascl1; glioblastoma; Notch; Wnt; cancer; differentiation; neuronal; self-renewal]

Supplemental material is available for this article.

Received October 22, 2018; revised version accepted February 19, 2019.

Many tumors contain a hierarchical structure reminiscent of a stem cell system, with more primitive and more therapy-resistant cell types, called cancer stem cells (CSCs), driving tumorigenicity and confounding therapeutic efficacy (Nguyen et al. 2012; Patel et al. 2014). In addition to demonstrating intratumoral heterogeneity, tumors from different patients also typically show specific mutations, structural alterations, or transcriptional programs that define individual features that make finding

\footnotetext{
${ }^{11}$ Present address: OCAD University, Toronto, Ontario M5T 1W1, Canada. ${ }^{12}$ These authors contributed equally to this work.

Corresponding authors: stephane.angers@utoronto.ca, peter.dirks@ sickkids.ca

Article published online ahead of print. Article and publication date are online at http://www.genesdev.org/cgi/doi/10.1101/gad.321968.118.
}

a unifying therapy for all patients within a given cancer challenging (Lan et al. 2017).

Among tumors of the central nervous system (CNS), glioblastoma (GBM) is the most malignant, with very poor prognosis and severe limitations in treatment options, currently still restricted to radiation and chemotherapy using the alkylating agent temozolomide. GBM follows a hierarchical structure, with a small population of cells identified to have functional and phenotypic

\footnotetext{
(C) 2019 Rajakulendran et al. This article is distributed exclusively by Cold Spring Harbor Laboratory Press for the first six months after the full-issue publication date (see http://genesdev.cshlp.org/site/misc/ terms.xhtml). After six months, it is available under a Creative Commons License (Attribution-NonCommercial 4.0 International), as described at http://creativecommons.org/licenses/by-nc/4.0/.
} 
similarities to neural stem cells (Galli et al. 2004; Singh et al. 2004; Tirosh et al. 2016; Lan et al. 2017) that are defined as GBM stem cells (GSCs). GSCs are resistant to chemotherapy and radiotherapy (Bao et al. 2006; Chen et al. 2012) and therefore contribute to tumor recurrence. It is therefore fundamentally important to understand the underlying biology of GSCs to develop new strategies to eliminate them along with the bulk of the tumor.

During embryonic development and adult tissue homeostasis, a recurrent number of signaling pathways controlled by secreted growth factors such as Notch, Wnt, Hedgehog, and TGF $\beta$ govern core processes in stem and progenitor cells that include self-renewal, proliferation, differentiation, and migration (Moore and Lemischka 2006; Clevers et al. 2014). Reactivation or subversion of these pathways in cancer frequently contributes to tumor progression as a result of uncontrolled growth, differentiation failure, or invasion (Dreesen and Brivanlou 2007; Azzarelli et al. 2018). Numerous studies, including fate mapping of in vivo barcoded primary GBM cells (Lan et al. 2017), strongly support the concept that GBM is driven by a growth process that is highly reminiscent of a developmental hierarchy based on rare stem cells. Interestingly, one of the biggest phenotypic differences with normal neural stem cells appears to be the decreased differentiation potential of GSCs following growth factor withdrawal. Strategies that overcome differentiation failure in GBM to restrict uncontrolled expansion of GSCs and favor generation of more mature cells with limited proliferative capacity may therefore represent attractive therapeutic opportunities. For example, we recently uncovered that a subset of GSCs expressing a relatively high level of the proneural transcription factor ASCL1 retains developmental neurogenic capacity (Park et al. 2017). We demonstrated that the latent neuronal differentiation potential of ASCL $1^{\text {hi }}$ GSCs can be therapeutically unmasked by modulating Notch signaling, using $\gamma$ secretase inhibitors, to promote neuronal differentiation, decrease self-renewal, and restrict their tumorigenic potential (Park et al. 2017).

In concert with Notch, Wnt/ $\beta$ catenin signaling is a critical regulator of stem and progenitor cell populations during embryonic development and adult tissue homeostasis. Mutations or defects in genetic or epigenetic mechanisms leading to dysregulated Wnt/ßcatenin signaling are frequent in human diseases and are at the root of a number of cancers, including brain neoplasms (Korinek et al. 1997; Zurawel et al. 1998; Anastas and Moon 2013). In humans, the Wnt signaling pathway is comprised of a network of 19 Wnt ligands and 10 Frizzled (FZD) receptors and several coreceptors, including LRP5/6, ROR1/2, PTK7, and RYK. When secreted Wnt proteins bind to the FZD-LRP5/6 receptor complex on the cell surface of receiving cells, this interaction leads to activation of the Wnt/ßcatenin pathway, also known as the canonical Wnt pathway, as this pathway was the first identified and is the best-understood Wnt protein signaling cascade (Steinhart and Angers 2018). Activation of the Wnt/ $\beta$ catenin pathway results in $\beta$ catenin proteins accumulating and translocating into the nucleus, where they interact with the LEF/TCF family of transcription factors to regulate context-dependent expression of Wnt target genes such as $A X I N 2$ and NKD1. In the developing brain, Wnt/ $\beta$ catenin signaling promotes NSC self-renewal and proliferation (Chenn and Walsh 2002; Lie et al. 2005; Kalani et al. 2008) and regulates the anterior-posterior patterning of the nervous system (Ciani and Salinas 2005). During later stages of neurogenesis, Wnt/ßcatenin signaling is required for specification of neuronal subtypes (Israsena et al. 2004; Kuwabara et al. 2009; Munji et al. 2011). Several studies have implicated dysregulated Wnt signaling in GBM despite the absence of genetic alterations within known pathway components such as APC or $\beta$ catenin (Reya and Clevers 2005). For example, the forkhead transcription factor FOXM1 promotes the nuclear translocation of $\beta$ catenin in GBM and contributes to pathway activation and GSC self-renewal (Hodgson et al. 2009; Zhang et al. 2011). In GSCs, Wnt signaling pathway components can be up-regulated indirectly due to genetic modifications in other genes such as overexpression of PLAGL2, which is necessary for self-renewal and can up-regulate Wnt signaling pathway members (Zheng et al. 2010). In addition, aberrant regulation of a transcriptional network controlled by ASCL1 represses DKK1 expression, a negative regulator of Wnt/ $\beta$ catenin signaling, and leads to increased Wnt signaling in GBM (Rheinbay et al. 2013). Supporting a functionally important role for the Wnt/ $\beta$ catenin pathway in GBM, small molecule inhibitors of the acyltransferase Porcupine (PORCN), which blocks the palmitoylation of Wnt proteins and consequently their secretion and activity, inhibit the proliferation and clonogenic potential of GSCs in vitro and tumor progression in vivo (Kahlert et al. 2015; Huang et al. 2016). This finding was also supported by the discovery that Wntless (WLS), which is also involved in Wnt ligand secretion, is highly expressed in gliomas, and knockout of WLS results in a reduction of proliferation, clonogenic growth, and invasion (Augustin et al. 2012).

In this study, we uncovered that Wnt/ $\beta$ catenin signaling is activated in a small proportion of cells in GBM that match properties of GSCs such as sphere-forming potential and expression of SOX2. Although Wnt/ $\beta$ catenin signaling is activated in all GSC cultures examined, we found that it was functionally important for self-renewal in only a subset of GSCs that harbors a gene expression profile matching the proneural GBM subgroup, which also exhibits high expression of ASCL1. Strikingly, we show that dual inhibition of Notch and Wnt signaling in ASCL1 ${ }^{\text {hi }}$ GSCs accelerates the timing and extent of neuronal differentiation, pointing to new combinatorial developmental therapeutic opportunities.

\section{Results \\ Heterogeneous activation of Wnt/ $\beta$ catenin signaling in primary GBM tumors and GSCs}

Developmental programs are frequently co-opted by cancer stem cells to stimulate their self-renewal, drive their proliferative activity, and modulate their differentiation 
potential (Takebe et al. 2015; Azzarelli et al. 2018). Given its pervasive roles in stem cell function and cancer, we set out to define the role of the Wnt/ßcatenin signaling pathway for GSC self-renewal. We first studied primary human GBM samples, which are known to contain subsets of tumor cells with tumor-propagating properties that are positive for the neural stem cell marker SOX2 (Singh et al. 2004; Pollard et al. 2009). Immunostaining of multiple primary patient samples identified a subset of $\mathrm{SOX}^{+}$ cells that was also positive for nuclear $\beta$ catenin staining, a standard proxy of Wnt pathway activation (Fig. 1A,B; Supplemental Fig. S1A). Notably, all nuclear $\beta$ cateninpositive cells were also positive for SOX2, suggesting that $1 \%-2 \%$ of SOX2-positive cells have active Wnt/ $\beta$ catenin signaling. We next quantified expression of activat- ed $\beta$ catenin by Western blot analysis of total protein lysates from stem cell-enriched fractions of primary GBM using an antibody specific for the dephosphorylated Ser37/Thr41 form of activated $\beta$ catenin, which is a more direct readout of Wnt pathway activity than nuclear staining. Freshly dissociated GBM cells enriched for CD15/ Lewis-x/SSEA-1 and CD133 (Son et al. 2009), which are known to contain a higher proportion of GBM tumorinitiating cells, had higher expression of activated $\beta$ catenin compared with the CD15- and CD133-negative cells isolated from the same freshly dissociated primary sample (Supplemental Fig. S1B). Together, these findings suggest that within GBM tumors, Wnt/ $\beta$ catenin activity is enriched in cells that have been previously defined to have tumorigenic properties.
A

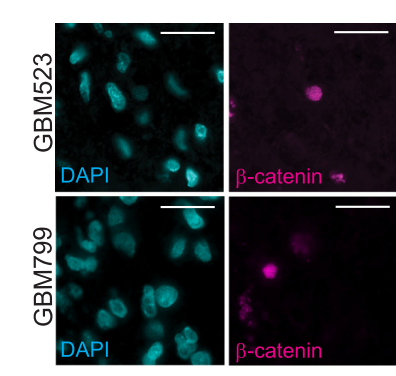

C
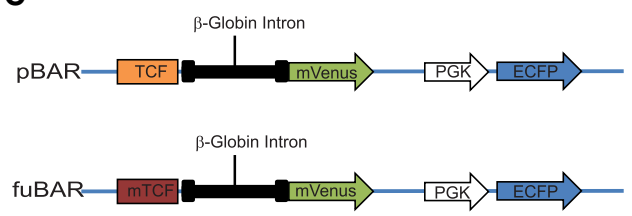

$\mathbf{F}$

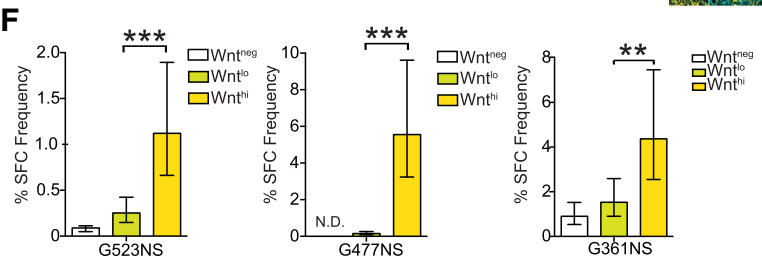

$\mathbf{G}$

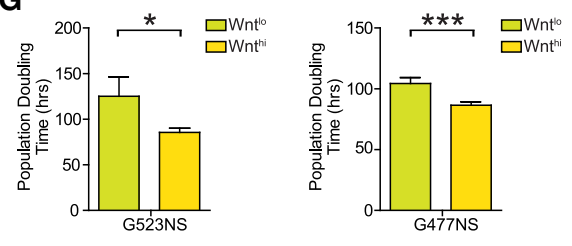

B

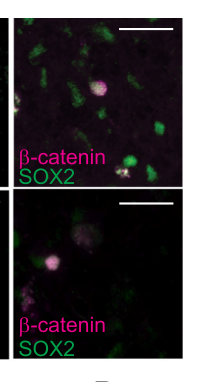

D

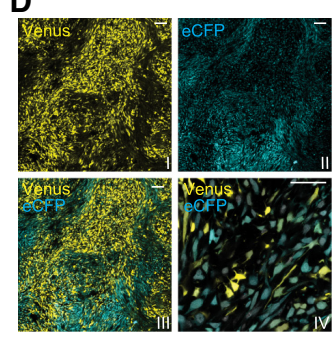

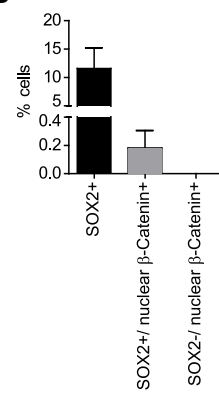

E

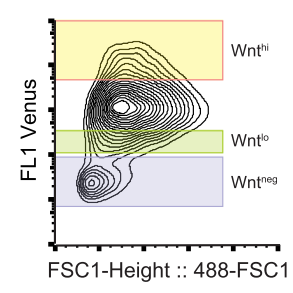

Figure 1. Wnt activity is enriched in GSCs. (A) Immunohistochemistry of primary GBM tumors stained for the stem cell marker SOX2 and $\beta$ catenin. Scale bar, $20 \mu \mathrm{m}$. (B) Average of SOX2 ${ }^{+}$and nuclear $\beta$ catenin ${ }^{+}$cells in five patient GBM tumor samples (GBM523, GBM799, GBM859, GBM620, and GBM798). Error bars indicate mean \pm SD. (C, top) Diagram of a pBarVenus reporter construct in which synthetic LEF-TCF-binding sites drive expression of Venus. (Bottom) A fuBarVenus construct in which the LEF-TCF-binding elements are mutated was used as control. $(D)$ Fluorescence of intracranial xenograft from a GSC culture transduced with pBarvenus reporter. Scale bars: $100 \mu \mathrm{m}$ (panels $I, I I, I I I) ; 50 \mu \mathrm{m}$ (panel $I V)$. (E) Fluorescence-activated cell sorting (FACS) analysis of pBarVenus intracranial xenografts. Wntneg, Wntlo, and Wnthi cells were sorted and analyzed. $(F)$ In vitro LDA of freshly dissociated Wntneg, Wntlo, and Wnthi GSCs. Error bars indicate estimated frequency $+95 \%$ CI. (N.D) Not detected. $\left(^{* *}\right) P<0.01 ;\left(^{* * *}\right) P<0.001$. (G) Population doubling times of Wntlo and Wnthi cells. Error bars indicate mean $\pm \mathrm{SD}$, unpaired $t$-test $\left(^{*}\right) P<0.05 ;\left({ }^{* * *}\right) P<0.001$. 
Following these observations, we sought to more closely study the intratumoral heterogeneity of $\beta$ catenin activity in GBM. When plated in serum-free medium containing EGF and FGF on a laminin substrate, a subpopulation of human GBM cells are expanded, retain stem cell phenotypes and functional properties, and are designated as GSCs (Pollard et al. 2009). We established primary GSC cultures expressing pBarVenus (Biechele et al. 2009), which has previously been described to faithfully report on $\beta$ catenin transcriptional activity (Fig. 1C, top). This reporter consists of synthetic LEF-TCF-binding sites driving the expression of the Venus fluorescent protein. As a control, we used fuBarVenus where the LEF-TCFbinding elements are mutated (mTCF) and Venus expression is therefore dissociated from $\beta$ catenin activity (Fig. 1C, bottom). When pBarVenus cells and fuBarVenus GSCs were treated with the GSK3 inhibitor BIO to activate Wnt- $\beta$ catenin signaling, an expected increase in Venus expression was selectively detected in pBARVenus-expressing GSCs (Supplemental Fig. S1C). We then introduced pBarVenus-expressing GSCs, isolated from three independent GBM patients, intracranially into NOD-SCID $\gamma$ (NSG) immunodeficient mice and let tumors develop until mice developed symptoms of tumor burden requiring sacrifice. Examination of freshly isolated GBM tumor cells from dissociated xenografts revealed varying degrees of Venus expression, indicating heterogeneous activation of Wnt/ $\beta$ catenin signaling (Fig. 1D; Supplemental Fig. S1D), consistent with our observations in freshly isolated primary human GBM tumors (Fig. 1A). Using flow cytometry, we then sorted for Venus expression and isolated the top $10 \%\left(\mathrm{Wnt}^{\mathrm{hi}}\right)$, lowest $10 \%\left(\mathrm{Wnt}^{\mathrm{lo}}\right)$, and negative (Wnt ${ }^{\text {neg }}$ ) fractions and plated these cells into limiting dilution analysis (LDA) to quantify the frequency of sphere-forming cells (SFCs; as a surrogate assay for selfrenewal) and proliferation assays (Fig. 1E,F,G; Supplemental Fig. S1E). For all tested GSCs (G477NS, G523NS, and G361NS), Wnt ${ }^{\text {hi }}$ cells had greater clonogenic potential and shorter doubling time relative to $\mathrm{Wnt}^{\text {lo }}$ cells (Fig. 1F, G). Wnt ${ }^{\text {neg }}$ cells did not proliferate once plated, and thus a doubling time could not be calculated. In contrast, cells isolated from control fuBarVenus-expressing xenografts showed no difference in sphere-forming ability when sorted for Venus ${ }^{\text {lo }}$ and Venus ${ }^{\text {hi }}$ populations (Supplemental Fig. $\mathrm{S} 1 \mathrm{E})$. Overall, our findings reveal heterogenous intratumoral activation of Wnt/ $\beta$ catenin signaling in GBM, where cells with the highest level of Wnt/ $\beta$ catenin signaling activity exhibit increased proliferation and higher SFC frequency, consistent with a more aggressive/tumorigenic phenotype.

Wht proteins are required for self-renewal of a subset of GSCs

Having established that Wnt signaling is heterogeneously activated in vivo, we set out to determine the role of Wnt signaling pathway activation in early-passage GSC cultures. In eight early-passage GSC cultures, we evaluated the functional roles of Wnt proteins using the small molecule Porcupine (PORCN) inhibitor LGK974, which blocks
PORCN-mediated palmitoylation of Wnt ligands, a posttranslational modification required for their secretion and activity. In all GSC cultures, LGK974 treatment led to decreased levels of the $\beta$ catenin target genes AXIN2 and $N K D 1$ (Fig. 2A), indicating that most early-passage GSCs exhibit ligand-dependent Wnt/ßcatenin signaling activity. To determine whether Wnt proteins were required for GSC clonogenic ability, we incubated GSC cultures with LGK974 for $1 \mathrm{wk}$ and then replated the cells in a LDA in the presence of LGK974. Interestingly, four out of eight primary GSC cultures tested showed a significant reduction in SFC frequency with LGK974 treatment, whereas four GSC cultures showed no effect (Fig. 2B) despite the treatment leading to effective inhibition of Wnt/ $\beta$ catenin signaling response as demonstrated above (Fig. 2A). Based on LGK974 sensitivity in these assays, we classified GSC cultures as Wnt-dependent or Wnt-independent. Wnt-dependent GSCs showed a dose-dependent decrease in SFC frequency when treated with LGK974 (Supplemental Fig. S2A) and also a statistically significant increase in doubling time (Supplemental Fig. S2B), whereas Wnt-independent GSCs showed no difference in doubling time (Supplemental Fig. S2B). To further establish a requirement for Wnt proteins for self-renewal in Wnt-dependent GSCs, we conducted a secondary LDA in which control cells and cells treated with LGK974 in the primary LDA were harvested and replated in a secondary LDA in the absence of LGK974. Treatment of two Wnt-dependent GSC cultures (G477NS and G523NS) with LGK974 led to significant reduction in secondary SFC frequency, demonstrating long-term inhibition of GSC self-renewal following PORCN inhibition (Fig. 2C). We also found a trend for increased levels of activated $\beta$ catenin in Wnt-dependent GSCs (Fig. 2D).

\section{Wnt-dependent GSCs exhibit a proneural signature}

Since we identified subsets of GSC cultures as Wnt-dependent and Wnt-independent, we next used RNA-seq to identify subset-specific gene expression signatures (Supplemental Table S1). Hierarchical clustering of gene expression data of eight GSC cultures indicated that the four Wnt-dependent GSC cultures clustered together and separately from the four Wnt-independent GSC cultures (Fig. 3A; Supplemental Fig. S3A). We identified subsets of genes that were significantly up-regulated or downregulated in Wnt-dependent and Wnt-independent GCS cultures (Fig. 3B; Supplemental Table S2) and describe a gene signature that could be used to predict reliance on Wnt ligands for self-renewal (Fig. 3A). Validation of five genes up-regulated in the Wnt-dependent group using qPCR confirmed the RNA-seq results (Fig. 3C; Supplemental Fig. S3B). Gene set enrichment analysis (GSEA) identified the proneural, classical, Wnt canonical, and Notch gene sets as enriched in Wnt-dependent GSCs (Fig. 3D). In contrast, in the Wnt-independent GSCs, the glioblastoma mesenchymal gene set was the top hit (Fig. 3C). Although the classical gene set was enriched in Wnt-dependent GSCs, based on false discovery rate (FDR) Q-value of our GSEA, we conclude that GSC 

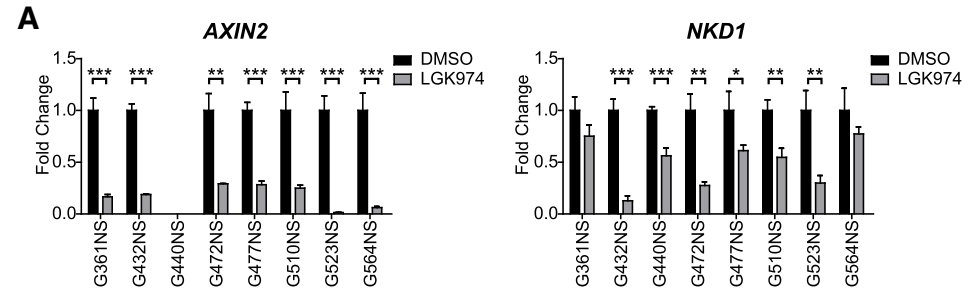

B
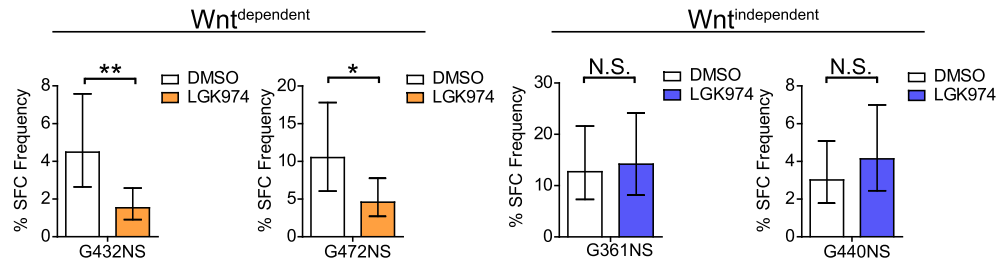

C Secondary Sphere Assay Wntdependent
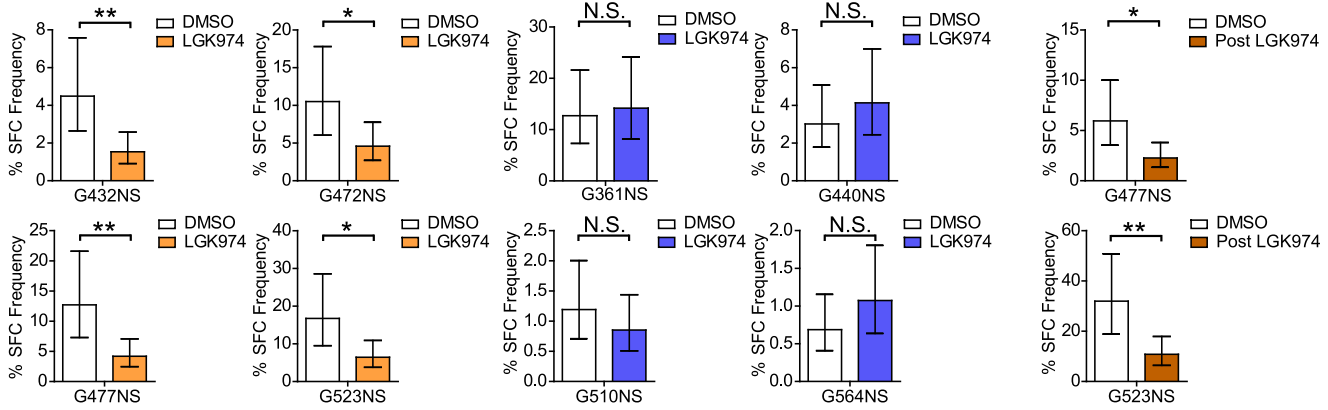

D

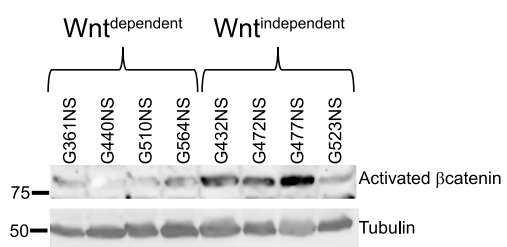

Figure 2. A subset of primary GNS cell lines requires Wnt signaling for self-renewal. (A) qPCR analysis of Wnt target genes AXIN2 and NKD1 in GSCs treated with the PORCN inhibitor LGK974 for 1 wk. Error bars indicate mean \pm SD. $\left.\left({ }^{*}\right) P<0.05 ;\left(^{* *}\right) P<0.01 ; i^{* * *}\right) P<0.001$. $(B)$ In vitro LDA of GSC cultures treated with $1 \mu \mathrm{M}$ LGK974. Error bars indicate estimated frequency $+95 \%$ CI. $\left({ }^{*}\right) P<0.05$; $\left(^{* *}\right) P<0.01$. (C) Post-LGK974 secondary in vitro LDA of GSC cultures after 1 wk of LGK974 treatment in 2D cultures and 1 wk of LGK974 treatment in primary LDA. Error bars indicate estimated frequency $+95 \%$ CI. $\left({ }^{*}\right) P<0.05 ;\left({ }^{* *}\right) P<0.01$. $(D)$ Western blot analysis of activated $\beta$ catenin in Wnt-dependent and Wnt-independent GSCs.

cultures harboring the TCGA proneural gene expression profile (FDR $<0.0001$ ) depend on Wnt proteins for self-renewal, whereas GSC cultures from the mesenchymal group (FDR < 0.0001) still exhibit active Wnt- $\beta$ catenin signaling but are not functionally reliant on this developmental pathway.

\section{Bcatenin-mediated transcriptional activity is required for self-renewal of a subset of GSCs}

Since Wnt ligands are known to regulate both $\beta$ catenin-dependent and $\beta$ catenin-independent signaling pathways, we next wanted to determine the requirement for $\beta$ catenin transcriptional regulation on GSC clonogenic potential. To do this, we interfered with the assembly of the $\beta c a t e n i n$ transcriptional complex using an inhibitor of $\beta c$ atenin-responsive transcription (iCRT14), which blocks the interaction between $\beta$ catenin and TCF7L2 (Gonsalves et al. 2011). iCRT14 treatment reduced the expression of Wnt target genes (Supplemental Fig. S4A) and led to decreased SFC frequency in Wnt-dependent GSCs (Fig. 4A). In support of these findings, we expressed a T-cell factor (TCF) dominant-negative protein (Vacik and Lemke
2011) that lacks the $\beta$ catenin-binding domain but maintains the DNA-binding domain (TCF7L2-DN) in GSC cultures. Expression of TCF7L2-DN inhibited the Wntmediated activation of a $\beta$ catenin-dependent luciferase reporter in HEK293 cells and GSCs (Supplemental Fig. S4B) and reduced expression of the Wnt target genes AXIN2 and NKD1 in Wnt-dependent and independent GSCs (Supplemental Fig. S4C). Consistent with a differential reliance on $\beta$ catenin signaling in Wnt-dependent versus Wnt-independent GSCs, expression of TCF7L2-DN only inhibited SFC frequency in Wnt-dependent GSCs (Fig. 4B). As an additional control, we also analyzed SFC frequency in cells expressing wild-type TCF7L2 versus TCF7L2-DN and had consistent findings where expression of TCF7L2-DN inhibited SFC frequency in Wntdependent GSCs (Supplemental Fig. S4D).

We next set out to test the requirement of Wnt $/ \beta$ catenin signaling for GBM growth in vivo. We injected control or TCF7L2-DN-expressing Wnt-dependent G523NS cells or Wnt-independent G361NS cells subcutaneously into the flanks of mice. The volume of the tumors was measured over time, and the mice were sacrificed at either $66 \mathrm{~d}$ or $35 \mathrm{~d}$ after initial injection for Wnt-dependent and Wnt- 
A

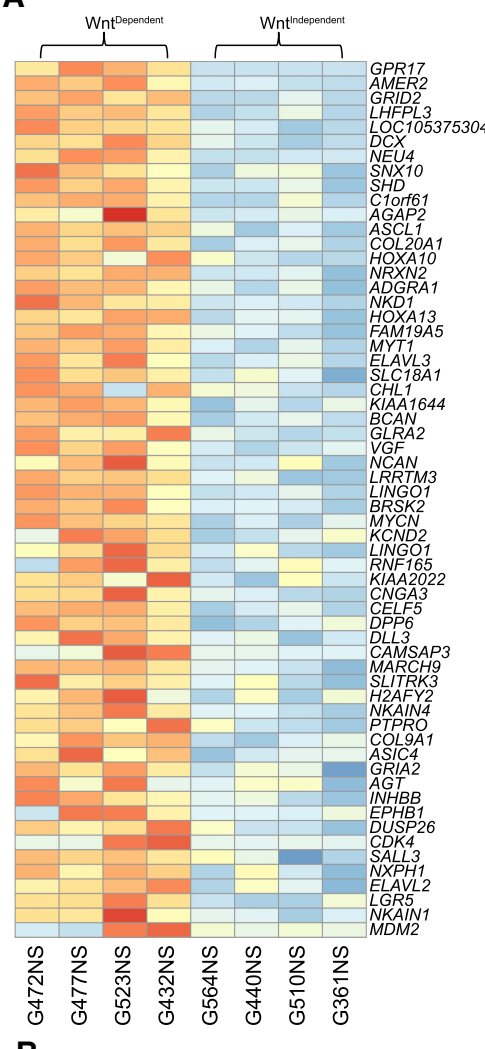

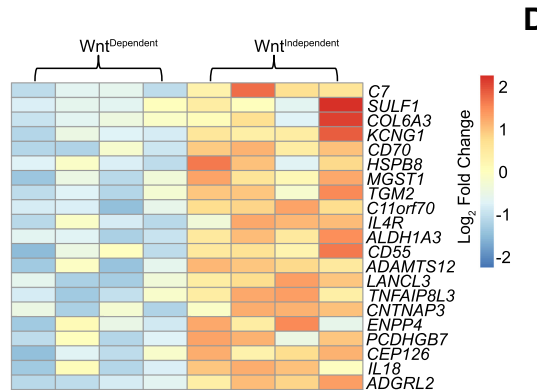
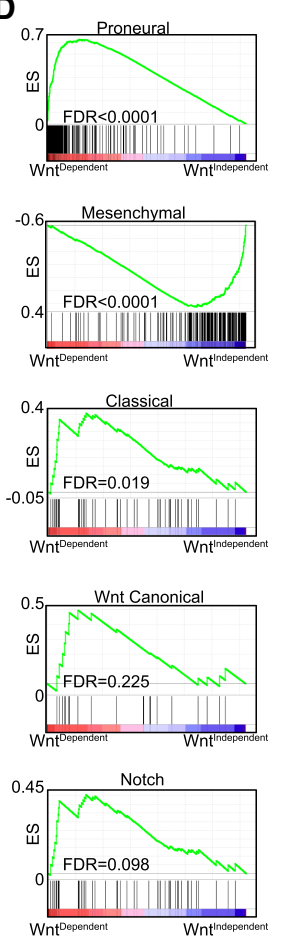

B
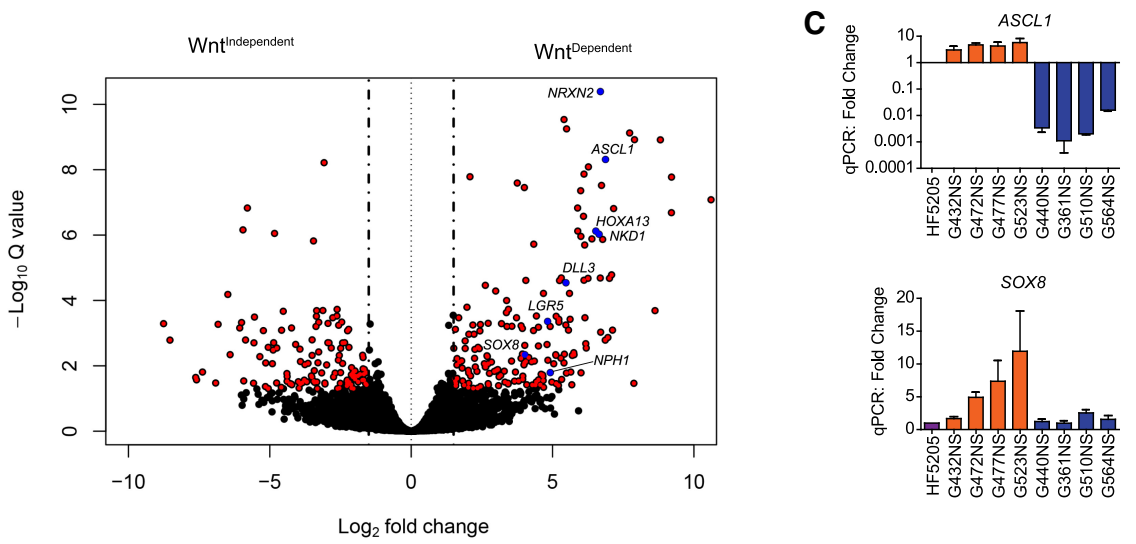

Figure 3. Classification of Wnt-dependent and Wnt-independent GSC cultures. (A) Heat map of differentially expressed genes in Wntdependent and Wnt-independent GSC cultures. Genes overexpressed (left) and underexpressed (right) in Wnt-dependent GSC cultures are shown. FDR $<1 \%$. (B) Volcano plot of differentially expressed genes in Wnt-dependent and Wnt-independent GSC cultures. $(C)$ qPCR analysis of selected genes identified to be differentially expressed in Wnt-dependent and Wnt-independent GSC cultures. Error bars indicate mean \pm SD. $(D)$ GSEA of differentially expressed genes in Wnt-dependent and Wnt-independent GNS cultures using RNA-seq.

independent cells, respectively. A significant reduction in weight and volume of TCF7L2-DN-expressing G523NSderived (Wnt-dependent) tumors relative to control tumors was observed (Fig. 4C; Supplemental Fig. S4E). In contrast, no significant difference in tumor weight or volume was observed between control and TCF7L2-DNexpressing tumors (Fig. 4C; Supplemental Fig. S4F).

To further confirm the importance of $\beta$ catenin signaling for the tumorigenicity of Wnt-dependent GSCs, we performed orthotopic intracranial transplantations of Wnt-dependent or Wnt-independent GSCs expressing TCF7L2-DN or a control plasmid and assessed survival. TCF7L2-DN expression conferred a significant survival benefit for mice injected with equivalent number of Wnt-dependent GSCs, whereas no significant difference was observed for mice injected with Wnt-independent GSCs (Fig. 4D). To confirm the on-target activity of the TCF7L2-DN protein, decreased expression of $\beta$ catenin 
A
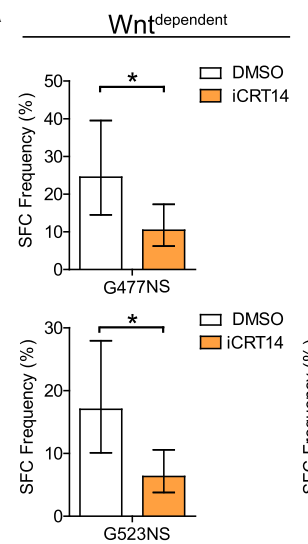

C

Subcutaneous Tumors

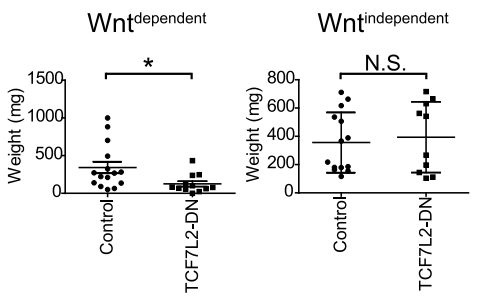

Wntindependent
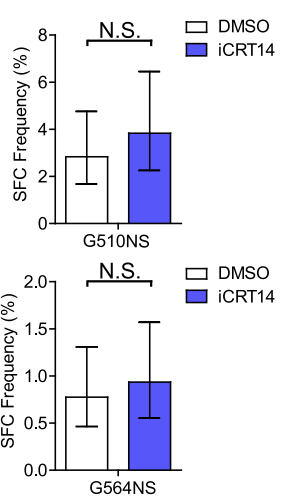

B
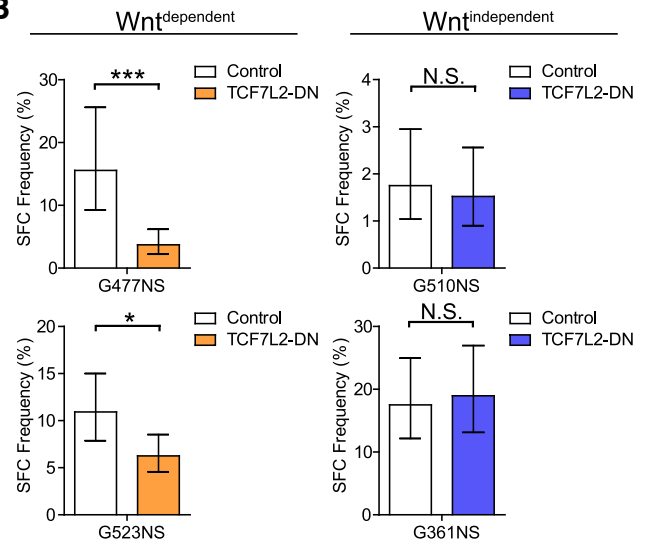

D
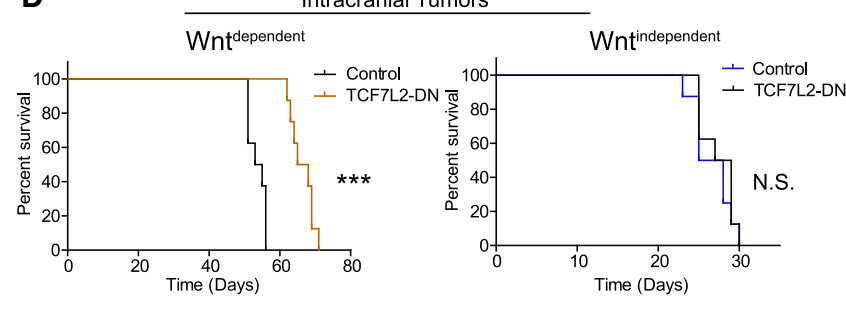

Figure 4. A subset of primary GSC cultures requires canonical Wnt signaling for self-renewal. $(A)$ In vitro LDA of GSC cultures treated with $1 \mu \mathrm{M}$ iCRT14 for 1 wk in 2D cultures. Error bars indicate estimated frequency $\pm 95 \%$ CI. $\left(^{*}\right) P<0.05$. (B) In vitro LDA of GSC cultures transduced with control or TCF7L2-DN virus. Error bars indicate estimated frequency $\pm 95 \%$ CI. $\left({ }^{*}\right) P<0.05$; $\left(^{* * *}\right) P<0.001$. $(C, 1$ left $)$ Quantification of tumor weights of subcutaneously transplanted Wnt-dependent G523NS-TCF7L2-DN $(n=12)$ and control (n=15) cultures. Error bars indicate mean \pm SEM. (Right) Quantification of tumor weights for subcutaneously transplanted Wnt-independent G361NSTCF7L2-DN $(n=10)$ and control $(n=14)$ cultures. Error bars indicate mean \pm SEM. $\left({ }^{*}\right) P<0.05$, unpaired $t$-test. $(D$, left $)$ Kaplan-Meier analysis for Wnt-dependent G477NS control $(n=8)$ or TCF7L2-DN $(n=8)$ cultures transplanted intracranially. (Right) Kaplan-Meier analysis of Wntindependent G361NS control $(n=8)$ or TCF7L2-DN $(n=8)$ cultures transplanted intracranially. $\left(^{* * *}\right) P<0.001$, Mantel-Cox test.

target genes in TCF7L2-DN-expressing GSCs was confirmed using qPCR prior to cell injection (Supplemental Fig. S4G). We conclude that although $\beta$ catenin-mediated transcriptional activation occurs in all GSC cultures examined, it is cell-autonomously required for the growth of only a subset of patient-derived GSCs.

\section{Dual Wnt and Notch signaling pathway inhibition accelerates and potentiates GSC neuronal differentiation}

Since the results above indicated that inhibition of Wnt/ $\beta c a t e n i n$ signaling decreased self-renewal capacity in a subset of GSCs, we next tested whether this was accompanied by increased GSC differentiation. Wnt-dependent and Wnt-independent GSC lines were treated with LGK974, and the percentage of GFAP-positive (astrocytic marker) and TUBB3-positive (neuronal marker) cells was quantified using immunofluorescence. We observed that inhibition of Wnt secretion with LGK974 led to a small but significant increase of GFAP-positive cells in two Wnt-dependent GSC cultures but had no effect in Wntindependent cultures (Fig. 5A,B; Supplemental Fig. S5A,B).

We demonstrated previously that a subset of GSC lines expresses high levels of Achaete-scute homolog 1 (ASCL1), a proneural transcription factor involved in nor- mal neurogenesis (Park et al. 2017). Compared with ASCL $1^{\text {lo }}$ GSCs, ASCL1 ${ }^{\text {hi }}$ GSCs display a latent potential for terminal neuronal differentiation in response to inhibition of Notch signaling or following withdrawal of self-renewal growth factors. Given the common proneural gene expression programs of ASCL $1^{\text {hi }}$ and Wnt-dependent GSCs (Fig. 3A,B), we hypothesized that dual inhibition of Wnt and Notch signaling may synergize to promote differentiation. Treatment of Wnt-dependent GSCs (ASCL1 ${ }^{\text {hi }}$ ),

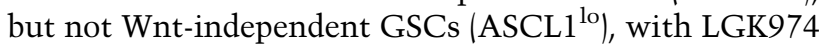
and the $\gamma$-secretase inhibitor (GSI) for a short period ( $2 \mathrm{wk}$ ) led to robust increases in TUBB3 staining, whereas GSI treatment alone was not sufficient to induce significant staining at this time point (Fig. 5C,D; Supplemental Fig. S5C,D). Furthermore, knockout of ASCL1 in ASCL1 ${ }^{\text {hi }}$ GSCs inhibited the neuronal differentiation observed with the treatment (Supplemental Fig. S5E). Increasing the treatment duration for a longer period ( $4 \mathrm{wk}$ ) led to substantial neuronal differentiation with GSI treatment alone in Wnt-dependent GSCs (Fig. 5D; Supplemental Fig. S5C, D). Importantly, LGK974 treatment significantly inhibited cell cycling, as measured using Ki67 staining, but GSI treatment had only a minimal effect in Wnt-dependent GSCs during the short treatment (Fig. 5D; Supplemental Fig. S5C-E). This synergy in the ability of Wnt and Notch pathway inhibitors to potentiate neuronal differentiation 
A
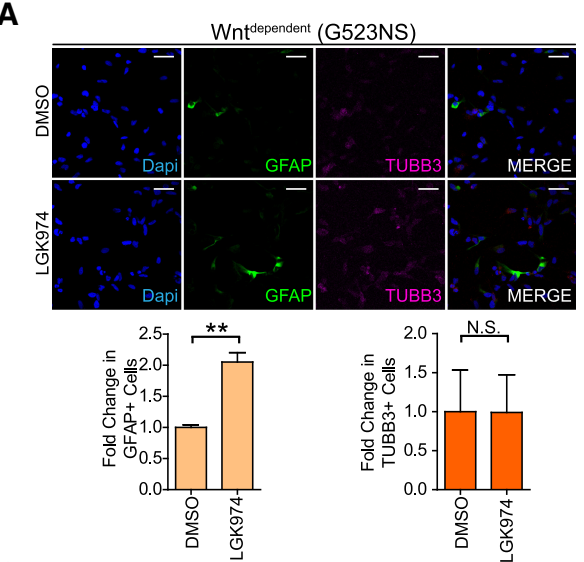

C
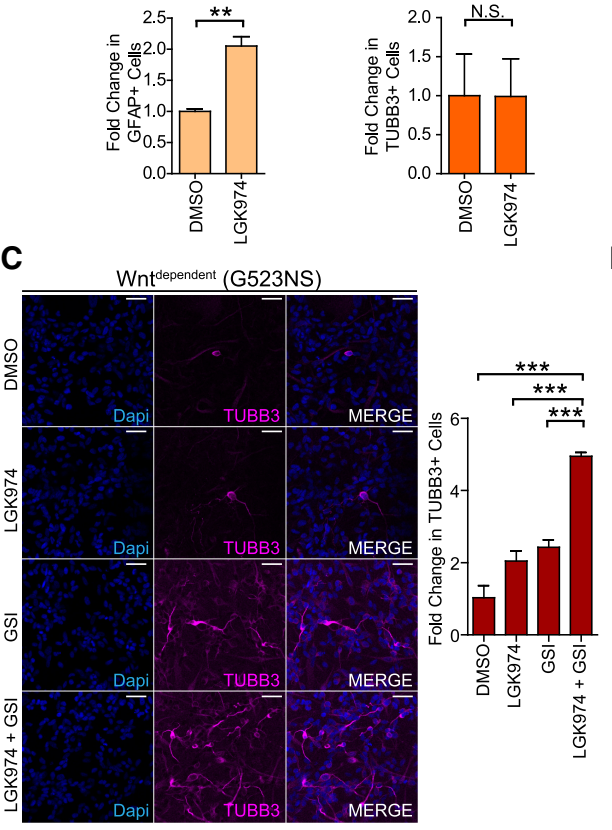

B
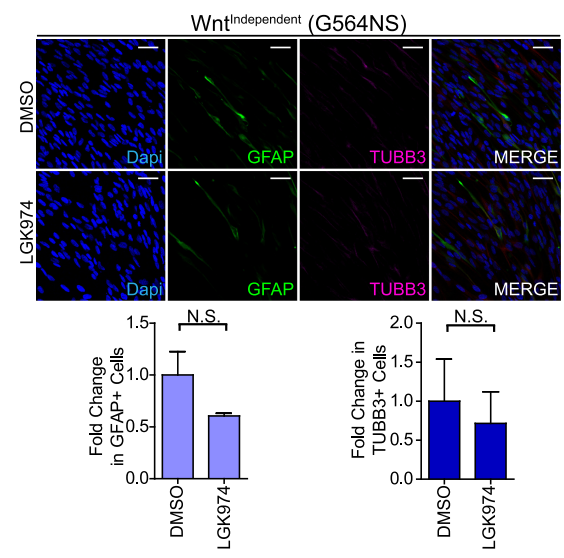

D

E

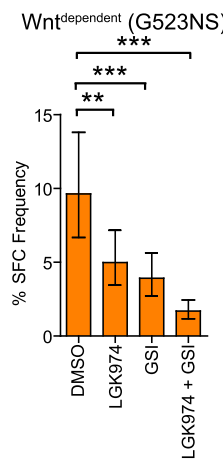

Wnt ${ }^{\text {Independent }}(\mathrm{G} 361 \mathrm{NS})$
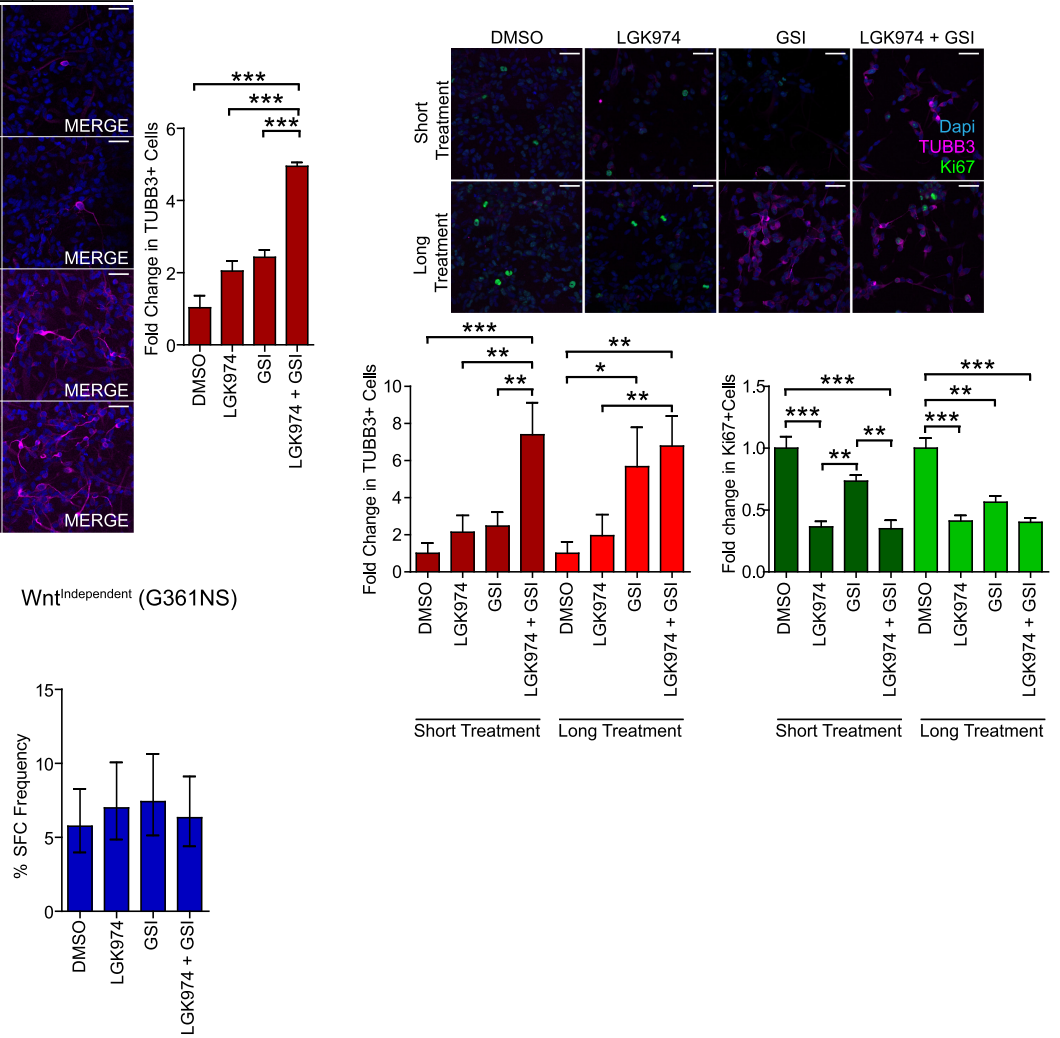

Figure 5. Wnt and Notch signaling maintain GSC cultures in an undifferentiated state. $(A, B$, top $)$ Immunohistochemistry of GFAP and TUBB3 in Wnt-dependent $(A)$ and Wnt-independent $(B)$ GSC cultures following treatment with $1 \mu$ M LGK974 for 2 wk. Quantification of $\mathrm{GFAP}^{+}$or TUBB3 ${ }^{+}$GSCs is shown at the bottom. Error bars indicate mean $\pm \mathrm{SD}\left({ }^{* *}\right) P<0.01$, unpaired $t$-test. Scale bar, $50 \mu \mathrm{m}$. $(C, 1 e f t) \mathrm{Im}$ munohistochemistry of TUBB3 in GSC cultures (G523NS) treated with $1 \mu \mathrm{M}$ LGK974 and/or $5.5 \mu \mathrm{M} \gamma$ secretase inhibitor GSI for 2 wk. Quantification of TUBB3 ${ }^{+}$cells is shown at the right. Error bars indicate mean \pm SD. $\left(^{* * *}\right) P<0.001$, one-way ANOVA. Scale bar, $50 \mu$ m. $(D)$ Immunocytochemistry of TUBB3 and Ki67 in GSC cultures (G523NS) treated with $1 \mu$ M LGK974 and/or $5.5 \mu M$ GSI for 2 wk (short treatment) or $4 \mathrm{wk}$ (long treatment). Quantification of TUBB3 ${ }^{+}$cells and Ki67 $7^{+}$cells is shown below. Error bars indicate mean $\pm \mathrm{SD}$. $\left.{ }^{*}\right) P<$ $0.05 ;\left(^{* *}\right) P<0.01 ;\left(^{* *}\right) P<0.001$, one-way ANOVA. Scale bar, $50 \mu \mathrm{m}$. (E) In vitro LDA of Wnt-dependent and Wnt-independent GSC cultures treated with $1 \mu \mathrm{M}$ LGK974 and/or $5.5 \mu \mathrm{M}$ GSI. Error bars indicate estimated frequency $\pm 95 \%$ CI. $\left({ }^{* *}\right) P<0.01 ;\left({ }^{* * *}\right) P<0.001$.

of Wnt-dependent/ASCL1 ${ }^{\text {hi }}$ GSC cultures translated to a marked decrease in SFC frequency when compared with the inhibitors used separately (Fig. 5E; Supplemental Fig. S5F). This effect on SFC frequency also required ASCL1, since treatment with LGK974 and GSI had no effect in Wnt-dependent GSCs in which ASCL1 was knocked out using CRISPR-Cas9 (Supplemental Fig. S5F). We conclude that dual inhibition of Wnt and Notch signaling, which results in block of GSC clonogenic potential and increased differentiation, respectively, accelerates the timing and potentiates neuronal differentiation when compared with GSI inhibitor alone. 


\section{Discussion}

Our findings support that GBMs retain developmental signaling axes that can be exploited to attenuate GSC selfrenewal and promote differentiation. Our data indicate that although Wnt/ $\beta$ catenin signaling is activated in all primary GSC cultures analyzed, it is required for self-renewal in only a subset of GSCs. Gene expression analysis revealed that Wnt-dependent GSCs have a transcriptional program most similar to the proneural GBM subset, whereas the Wnt-independent GSC cultures more closely resemble the mesenchymal GBMs, consistent with a recent report (Huang et al. 2016). Our own analysis of the chromatin state of primary GBM GSC cultures supports retention of developmental transcription factor networks essential for functional responses to developmental signaling modifiers (Lan et al. 2017), but, in this study, we show only a GBM subset retains Wnt-responsiveness.

Functional association between the proneural factor ASCL1 and Wnt signaling was uncovered previously, where ASCL1 expression leads to activation of Wnt signaling through repression of the negative regulator DKK1 (Rheinbay et al. 2013). Interestingly, our group has recently identified that ASCL1 expression in GBM follows a binary pattern of high and low expression (Park et al. 2017). GSEA revealed that the ASCL1 ${ }^{\text {hi }}$ subgroup is associated with the proneural GBM phenotype, whereas the ASCL $1^{\text {lo }}$ is associated with the mesenchymal phenotype. ASCL $1{ }^{\text {hi }}$ GSCs were found to exhibit a latent capacity for neuronal differentiation in response to Notch signaling inhibition, whereas ASCL1 ${ }^{\text {lo }}$ GSCs did not.

Together, our results therefore suggest that in ASCL $1{ }^{\text {hi }}$ GSCs, Wnt/ßcatenin and Notch signaling cooperate and contribute to tumor progression by promoting clonogenic ability, stimulating proliferation, and inhibiting differentiation. Consistent with this observation, we show that combined treatment of this GSC subgroup with both LGK974 and GSI results in more potent effects on clonogenic potential and differentiation. We hypothesize that ASCL $1{ }^{\text {hi }}$ GSCs have preserved a requirement on developmental signaling pathways to control the balance of clonogenic potential and differentiation, whereas ASCL $1^{\text {lo }}$ cells have escaped these developmental signals possibly through acquisition of additional mutations or epigenetic changes. Alternatively, the requirements on developmental signals may reflect a distinct cell of origin or a developmental memory for fate determination or a specific niche interaction that persists within the neoplastic context. We do not exclude that other developmental pathways (noncanonical Wnt or non-Notch) may be operative in the GBMs that show fewer proneural features.

These studies are also consistent with our recent observations that many GBMs pervasively maintain developmental hierarchies that cross-cut intratumoral or intertumoral mutational complexity (Lan et al. 2017), suggesting that broad developmental signaling pathways may be more important for patient targeting in this disease than targeting one or several mutant proteins that are heterogeneously expressed within individual patient tumors. Our results also predict that combining developmental signaling modifications that target both self-renewal and differentiation processes together, both of which are nearly universally altered in GBM, is likely to be a more successful strategy than targeting one of these processes alone, at least for a significant GBM subset, and we think approaches such as this deserve more preclinical focus.

\section{Materials and methods \\ Primary cell isolation and cell cultures}

Primary cells from GBMs were isolated from newly diagnosed or recurrent patient specimens following resection using an established protocol (Singh et al. 2004). In brief, human GBM surgical specimens were mechanically dissociated in artificial cerebrospinal fluid and incubated in enzymes for $30-40 \mathrm{~min}$ at $37^{\circ} \mathrm{C}$ with nutation in the presence of glass beads. After centrifugation, the supernatant was removed, and the pellet was resuspended in Dulbecco's modified Eagle's medium (Thermo Fisher). The pellet was pipetted to mechanically separate cell aggregates and passed through a $40-\mathrm{mm}$ mesh followed by centrifugation for $5 \mathrm{~min}$. Dissociated cells were plated and grown adherently on poly-L-ornithine-coated (Millipore Sigma) and laminin-coated (Millipore Sigma) primaria cell culture dishes (Corning) in Neurocult NS-A basal medium (Stem Cell Technologies) supplemented with GlutaMAX (Thermo Fisher), B27 (Thermo Fisher), N2 (Thermo Fisher), $150 \mu \mathrm{g} / \mathrm{mL}$ BSA (Thermo Fisher), $10 \mathrm{ng} /$ $\mathrm{mL}$ basic fibroblast growth factor (bFGF) (Thermo Fisher), $10 \mathrm{ng} / \mathrm{mL}$ recombinant human epidermal growth factor (rhEGF) (Thermo Fisher), and $2 \mu \mathrm{g} / \mathrm{mL}$ heparin (Millipore Sigma) as described previously (Pollard et al. 2009). Cells were dissociated using Accutase (Thermo Fisher). Where applicable, puromycin antibiotic was used at $2 \mu \mathrm{g} / \mathrm{mL}$. HEK293T cells were grown in DMEM supplemented with $10 \%$ FBS. The following drugs, when used, were dissolved in DMSO: (2'Z, $\left.3^{\prime} \mathrm{E}\right)$-6-bromoindirubin-3'-oxime (BIO, Millipore Sigma), LGK974 (AddoQ), and iCRT14 (Millipore Sigma).

Animals-xenograft models

NOD.Cg-PrkdcscidIl2rgtm1Wjl/SzJ (NSG) female mice 5-8 wk old from the Jackson Laboratory were used for all in vivo studies. For subcutaneous xenograft studies, 1 million cells were dissociated and injected into flanks of NSG mice. Mice were sacrificed once flank tumors reached a maximum diameter of $20 \mathrm{~mm}$. Tumors were removed and flash-frozen. For orthotopic transplantation, NSG mice were anesthetized using gaseous isoflurane and immobilized using a Kofp stereotactic apparatus with a mouse adapter. Following an incision at the midline, a 21-guage needle was used to drill a borehole $1 \mathrm{~mm}$ lateral and $2 \mathrm{~mm}$ posterior to bregma. Using a 27-guage needle Hamilton syringe, cells were injected $2.5 \mathrm{~mm}$ deep from the surface of the skull slowly for $3 \mathrm{~min}$. The needle was left for an additional 4 min to prevent reflux and then slowly removed over a period of $3 \mathrm{~min}$. Wax was used to fill up the borehole, and the incision at the midline was closed using sutures. Mice were observed daily for signs of neurological deficits and sacrificed for up to 6 mo. The Hospital for Sick Children's Animal Care Committee approved all experiments and procedures.

Transfections and lentiviral transductions

Lentiviral particles were produced in HEK293T cells. HEK293T were cotransfected with $2 \mu \mathrm{g}$ of vesicular stomatitis virus 
glycoprotein, $5 \mu \mathrm{g}$ of psPAX2, and $5 \mu \mathrm{g}$ of lentiviral vector in $30 \%-40 \%$ confluent cultures grown in $10-\mathrm{cm}$ plates using calcium phosphate. Fresh medium was added $24 \mathrm{~h}$ later, and medium containing viral particles was collected $48 \mathrm{~h}$ after initial transfection. Viral supernatant was collected and centrifuged briefly and filtered through a 0.45 - $\mu \mathrm{m}$ filter to remove cells and debris. Supernatant was then mixed with Lenti-X concentrator and incubated for a minimum of $2 \mathrm{~h}$ at $4^{\circ} \mathrm{C}$. The sample was then centrifuged at $1500 \mathrm{~g}$ for $45 \mathrm{~min}$, and a high-titer virus-containing pellet was resuspended in $200 \mu \mathrm{L}$ of DMEM/F12 (Thermo Fisher). GSCs were transduced with virus in the presence of $0.8 \mu \mathrm{g} / \mathrm{mL}$ polybrene, and viral medium was replaced with fresh medium containing $2 \mu \mathrm{g} / \mathrm{mL}$ puromycin when selection was possible.

\section{Limiting dilution assay}

In vitro sphere-forming ability was measured in a LDA where cells were plated in nonadherent 96-well plates in a limited dilution (range of 3-2000) with or without drug treatment. After 1-2 wk, the number of wells with at least one positive sphere (top of sphere contains five to eight cells) was counted, and the frequency of sphere-forming cells was determined by the inverse of the $x$ intercept of the regression between the number of wells negative for spheres and cells seeded per well. Colony-forming ability was quantified by Poisson statistics at $37 \%$ negative wells, and Extreme limiting dilution analysis (ELDA) software (http://bioinf .wehi.edu.au/software/elda) was used (Hu and Smyth 2009). All LDA experiments shown are representative experiments and were repeated a minimum of three independent times using early-passage GSC lines.

\section{TopFlash reporter assay}

Stable HEK293T cells expressing the TopFlash $\beta$ catenin-dependent luciferase reporter and Renilla luciferase (Lui et al. 2011) were transfected with control or TCF7L2-DN plasmid using polyethylenimine. The medium was replaced with a 1:1 ratio of fresh DMEM/Wnt3a or DMEM/control conditioned medium, and cells were assayed $24 \mathrm{~h}$ later using the dual-luciferase assay protocol (Promega) using the Envision multilabel plate reader. All TopFlash assays are an average of three replicates.

\section{Histology, immunofluorescence microscopy, and image acquisition}

Cells were grown on coverslips and fixed with $4 \%$ PFA for $10 \mathrm{~min}$. Cells were washed with PBS, permeabilized with $0.4 \%$ Triton X100 in PBS for $15 \mathrm{~min}$, and blocked with $1 \%$ goat serum and $0.2 \%$ Trion X-100 in PBS (blocking solution) for $1 \mathrm{~h}$. The cells were incubated with primary antibodies overnight at $4^{\circ} \mathrm{C}$ in blocking solution. Primary antibodies used in this study included TUBB3 (TU-20 mouse anti-Tubulin, $\beta$ III isoform; 1:500; Millipore Sigma), GFAP (1:500; DAKO), and Ki67 (SP6; 1:500; Thermo Fisher). The following day, the cells were washed with PBS, incubated with fluorophore-conjugated secondary antibodies for $1 \mathrm{~h}$ at room temperature, washed with PBS, and mounted onto slides using VectaShield mounting medium containing DAPI (Vector Laboratories). Images were acquired using a confocal microscope (Carl Zeiss, LSM 700) operated with ZEN software. The fraction of TUBB3-, GFAP-, or Ki67-positive cells was counted from five independent images from each condition. The average and standard deviation were calculated from three biological replicates.

Tissue samples were fixed in $4 \%$ paraformaldehyde for $24 \mathrm{~h}$ followed by paraffin embedding and sectioning. The sections were deparaffinized and rehydrated using an alcohol gradient to water for antigen retrieval in $10 \mathrm{mM}$ citrate buffer ( $\mathrm{pH}$ 6.0) in a micro- wave pressure cooker. Sections were then treated with $3 \%(\mathrm{v} / \mathrm{v})$ peroxide in methanol for $15 \mathrm{~min}$ at room temperature to block endogenous peroxide activity. Two percent $(\mathrm{v} / \mathrm{v})$ normal goat serum or horse serum (Vector Laboratories) in PBS with $2 \%(\mathrm{w} / \mathrm{v})$ BSA was used to block nonspecific binding. Primary antibodies SOX2 (1:1000; Abcam, ab97956) and $\beta$ catenin (1:200; BD Biosciences, 610153) were incubated overnight at $4^{\circ} \mathrm{C}$. Following washes, samples were incubated with fluorophore-conjugated secondary antibodies and imaged. SOX2- and/or $\beta$ catenin-positive cells were counted from five independent images from each sample, and the average and standard deviation were calculated from five different tumor samples.

\section{Western blotting}

Cellular protein from cultured cells and xenograft tumors were homogenized in RIPA lysis buffer with a mixture of protease (Roche) and phosphatase (Millipore Sigma) inhibitors. Protein concentration was determined using the Bradford assay (BioRad), and samples were run on a 7\% PAGE gel. Primary antibodies used were mouse antinonphosphorylated (Ser37/Thr41) $\beta$ cate$\operatorname{nin}(8 \mathrm{E} \&, 1: 500$; MilliporeSigma), mouse anti- $\beta$-actin $(1: 10,000$; MilliporeSigma), and $\beta$-Tubulin (E7, University of Iowa Developmental Studies Hybridoma Bank). Membranes were probed with horseradish peroxidase-linked donkey anti-mouse IgG (1:40,000; Millipore Sigma), and detection of protein was conducted using ECL Western blotting detection reagent (Thermo Fisher). All Western blots are representative images from a minimum of three biological replicates.

Reverse transcription PCR, qPCR, and RNA-seq analysis

RNA was isolated from cells using TRIzol (Thermo Fisher) following the manufacturer's instructions. Two micrograms of total RNA was reverse-transcribed for cDNA synthesis using the SuperScript II reverse transcription kit (Thermo Fisher). Real-time PCR was conducted using SyBr Green (Thermo Fisher) in a 7900HT Fast real-time PCR system. The $\Delta \Delta \mathrm{Ct}$ normalized to cyclophilin mRNA was used to quantify relative gene expression (Bookout et al. 2006). The primer sequences used were as follows: CYCLOPHILIN (5'-GGAGATGGCACAGGAGGAA- $3^{\prime}$ and $5^{\prime}$-GCCCGT AGTGCTTCAGTTT-3'), NKD1 (5'-TGAGAAGAAGATGGAG AGAGTGAGCGA-3' and $5^{\prime}$-GGTGACCTTGCCGTTGTTGTC AAA- $\left.3^{\prime}\right)$, and AXIN2 (5'-CTCCCCACCTTGAATGAAGA- $3^{\prime}$ and 5'-TGGCTGGTGCAAAGACATAG-3').

All qPCR experiments are shown as an average of a minimum of three replicates.

For generation of the RNA-seq library, RNA was isolated using TRIzol (Thermo Fisher), and 1 vol of $70 \% \mathrm{EtOH}$ was mixed with the aqueous phase. The sample was then passed through an RNeasy column (Qiagen) and washed following the manufacturer's instructions. RNA-seq libraries were derived using TruSeq V2 mRNA-enriched library kit (Illumina) following the manufacturer's protocol. Libraries were sequenced using HiSeq 2500 with $50-$ bp single-end reads. RNA-seq reads were processed with the RNA-seq bioinformatics pipeline of BCBIO toolkit (https:// github.com/chapmanb/bcbio-nextgen). Splicing-aware alignment was conducted using STAR (Dobin et al. 2013), and read count calculation was performed with featureCounts (Liao et al. 2014). Differential expression analysis was performed with edgeR package (Robinson et al. 2010; McCarthy et al. 2012) in R according to the user's guide (https://bioconductor.org/packages/ release/bioc/vignettes/edgeR/inst/doc/edgeRUsersGuide.pdf). The gene set enrichment analysis was performed with GSEA (Mootha et al. 2003; Subramanian et al. 2005). The parameters 
used were as follows: gene set database: c2.cgp.v6.0.symbols.gmt; permutation type: gene_set. Hierarchical clustering of GSC RNAseq data was performed using the pheatmap package in $\mathrm{R}$. The top 500 most variably expressed genes by interquartile range were used as input for average linkage clustering with Pearson correlation distance measurement. This data set is available through Gene Expression Omnibus (GEO; accession no. GSE126840).

In vitro cell proliferation assays

Proliferation assays were conducted in 24-well Primaria plates (Corning). Cells were lifted using Accutase (Thermo Fisher), and the number of live cells was quantified using Trypan Blue dye exclusion assay. Cells were counted over $2-3 \mathrm{wk}$, population doubling times were calculated using two time points during logarithmic growth phase, and the average was calculated from a minimum of three biological replicates.

Flow cytometry

Immediately following tumor dissociation into single-cell suspension, cells were fixed with $4 \%$ paraformaldehyde for $10 \mathrm{~min}$, permeabilized in $5 \%$ BSA and $0.1 \%$ saponin/PBS, and stained for $30 \mathrm{~min}$ in $5 \% \mathrm{BSA}, 4 \mathrm{mM}$ EDTA, and $15 \mathrm{mM}$ HEPES/PBS with anti-CD15 (BD) and CD133 (Miltenyi Biotech). Flow was performed on a BD LSR II analytical cytometer, and data were analyzed with FlowJo 7.6.3 software. For live-cell sorting, after cells were collected and dissociated into single cells by mechanical and enzymatic dissociation, mouse cells were depleted using the mouse cell depletion kit (Miltenyi Biotec). Cells were then resuspended in Hank's balanced salt solution (HBSS) calcium- and magnesium-free containing $10 \mathrm{mM}$ HEPES (pH 7.2) and $1 \mathrm{mM}$ EDTA. Live cells were selected using forward scatter (FSC) and side scatter (SSC), and doublets were removed. Venus-null and CFP-null cells were used for gating Venus- and CFP-positive cells.

\section{Statistical analysis}

Statistical details of experiments are in the figure legends and/or the Materials and Methods. Unless indicated otherwise, all statistical tests were performed using Graphpad Prism 5 and were two-sided (GraphPad Software). Data are expressed as mean \pm standard error unless stated otherwise. The results were analyzed by Student's $t$-test or ANOVA followed by post hoc analysis, as appropriate. Survivals were analyzed using the Kaplan-Meier method with the Mantel-Cox log-rank test. Significance was defined at $P<0.05$.

\section{Acknowledgments}

We thank Dr. Melanie Robitaille and Dr. Mukhtar Ahmed for generating pBARVenus and fuBarVenus plasmids. P.B.D.'s research was supported by SU2C Canada Cancer Stem Cell Dream Team Research Funding (SU2C-AACR-DT-19-15) provided by the Government of Canada through Genome Canada and the Canadian Institute of Health Research (142434), with supplemental support from the Ontario Institute for Cancer Research through funding provided by the Government of Ontario, and grants from the Canadian Cancer Society Research Institute and the Hospital for Sick Children Foundation. P.B.D. holds a Garron Family Chair in Childhood Cancer Research at the Hospital for Sick Children. This work was also supported through a "Targeting High Fatality Cancers-Innovation Grant" funded by the Canadian Institutes for Health Research to S.A. (CIHR-361837). N.R. and K.J.R. were also supported by Brain Canada-Canadian Imperial Bank of Commerce (CIBC) Brain Cancer Training Awards. S.A. holds a Canada Research Chair in Functional Architecture of Signal Transduction.

Author contributions: P.B.D., S.A, N.R., and K.J.R. conceptualized the study. N.R., K.J.R., M.A., N.I.P., H.J.S., R.J.W., S.D., C.B., and C.P. performed the in vitro experiments. K.J.R., H.J.S., L.L., and M.S. performed the in vivo experiments. S.N., G.M., and N.B. analyzed RNA-seq data. P.B.D., M.B., and M.D.C. provided the GBM cultures. S.A. and P.B.D. supervised the study and acquired funding for research. G.M., I.D.C., and N.I.P. provided input for the study and reviewed the manuscript. S.A., P.B.D., N.R., and K.J.R. wrote the manuscript with input from all authors.

\section{References}

Anastas JN, Moon RT. 2013. WNT signalling pathways as therapeutic targets in cancer. Nat Rev Cancer 13: 11-26. doi:10 $.1038 / \mathrm{nrc} 3419$

Augustin I, Goidts V, Bongers A, Kerr G, Vollert G, Radlwimmer B, Hartmann C, Herold-Mende C, Reifenberger G, von Deimling A, et al. 2012. The Wnt secretion protein Evi/Gpr177 promotes glioma tumourigenesis. EMBO Mol Med 4: 38-51. doi:10.1002/emmm.201100186

Azzarelli R, Simons BD, Philpott A. 2018. The developmental origin of brain tumours: a cellular and molecular framework. Development 145: dev162693. doi:10.1242/dev.162693.

Bao S, Wu Q, McLendon RE, Hao Y, Shi Q, Hjelmeland AB, Dewhirst MW, Bigner DD, Rich JN. 2006. Glioma stem cells promote radioresistance by preferential activation of the DNA damage response. Nature 444: 756-760. doi:10.1038/nature05236

Biechele TL, Adams AM, Moon RT. 2009. Transcription-based reporters of Wnt/ $\beta$-catenin signaling. Cold Spring Harb Protoc 2009: db.prot5223. doi:10.1101/pdb.prot5223

Bookout AL, Cummins CL, Mangelsdorf DJ, Pesola JM, Kramer MF. 2006. High-throughput real-time quantitative reverse transcription PCR. Curr Protoc Mol Biol 73: 15.8.1-15.8.28. doi:10.1002/0471142727.mb1508s73

Chen J, Li Y, Yu T-S, McKay RM, Burns DK, Kernie SG, Parada LF. 2012. A restricted cell population propagates glioblastoma growth after chemotherapy. Nature 488: 522-526. doi:10 $.1038 /$ nature 11287

Chenn A, Walsh CA. 2002. Regulation of cerebral cortical size by control of cell cycle exit in neural precursors. Science 297: 365-369. doi:10.1126/science.1074192

Ciani L, Salinas PC. 2005. Signalling in neural development: WNTs in the vertebrate nervous system: from patterning to neuronal connectivity. Nat Rev Neurosci 6: 351. doi:10 $.1038 / \mathrm{nrn} 1665$

Clevers H, Loh KM, Nusse R. 2014. Stem cell signaling. An integral program for tissue renewal and regeneration: Wnt signaling and stem cell control. Science 346: 1248012. doi:10.1126/ science. 1248012

Dobin A, Davis CA, Schlesinger F, Drenkow J, Zaleski C, Jha S, Batut P, Chaisson M, Gingeras TR. 2013. STAR: ultrafast universal RNA-seq aligner. Bioinformatics 29: 15-21. doi:10 .1093/bioinformatics/bts635

Dreesen O, Brivanlou AH. 2007. Signaling pathways in cancer and embryonic stem cells. Stem Cell Rev 3: 7-17. doi:10 $.1007 / \mathrm{s} 12015-007-0004-8$

Galli R, Binda E, Orfanelli U, Cipelletti B, Gritti A, De Vitis S, Fiocco R, Foroni C, Dimeco F, Vescovi A. 2004. Isolation and characterization of tumorigenic, stem-like neural 
precursors from human glioblastoma. Cancer Res 64: 70117021. doi:10.1158/0008-5472.CAN-04-1364

Gonsalves FC, Klein K, Carson BB, Katz S, Ekas LA, Evans S, Nagourney R, Cardozo T, Brown AMC, DasGupta R. 2011. An RNAi-based chemical genetic screen identifies three small-molecule inhibitors of the Wnt/wingless signaling pathway. Proc Natl Acad Sci 108: 5954-5963. doi:10.1073/pnas .1017496108

Hodgson JG, Yeh R-F, Ray A, Wang NJ, Smirnov I, Yu M, Hariono S, Silber J, Feiler HS, Gray JW, et al. 2009. Comparative analyses of gene copy number and mRNA expression in glioblastoma multiforme tumors and xenografts. Neuro Oncol 11: 477487. doi:10.1215/15228517-2008-113

$\mathrm{Hu}$ Y, Smyth GK. 2009. ELDA: extreme limiting dilution analysis for comparing depleted and enriched populations in stem cell and other assays. I Immunol Methods 347: 70-78. doi:10 $.1016 /$ j.jim.2009.06.008

Huang T, Alvarez AA, Pangeni RP, Horbinski CM, Lu S, Kim S-H, James CD, Raizer J J, Kessler J A, Brenann CW, et al. 2016. A regulatory circuit of $\mathrm{miR}-125 \mathrm{~b} / \mathrm{miR}-20 \mathrm{~b}$ and Wnt signalling controls glioblastoma phenotypes through FZD6-modulated pathways. Nat Commun 7: 12885. doi:10.1038/ncomms12885

Israsena N, Hu M, Fu W, Kan L, Kessler JA. 2004. The presence of FGF2 signaling determines whether $\beta$-catenin exerts effects on proliferation or neuronal differentiation of neural stem cells. Dev Biol 268: 220-231. doi:10.1016/j.ydbio.2003.12.024

Kahlert UD, Suwala AK, Koch K, Natsumeda M, Orr BA, Hayashi M, Maciaczyk J, Eberhart CG. 2015. Pharmacologic Wnt inhibition reduces proliferation, survival, and clonogenicity of glioblastoma cells. I Neuropathol Exp Neurol 74: 889-900. doi:10.1097/NEN.0000000000000227

Kalani MYS, Cheshier SH, Cord BJ, Bababeygy SR, Vogel H, Weissman IL, Palmer TD, Nusse R. 2008. Wnt-mediated self-renewal of neural stem/progenitor cells. Proc Natl Acad Sci 105: 16970-16975. doi:10.1073/pnas.0808616105

Korinek V, Barker N, Morin PJ, van Wichen D, de Weger R, Kinzler KW, Vogelstein B, Clevers H. 1997. Constitutive transcriptional activation by a $\beta$-catenin-Tcf complex in $\mathrm{APC}^{-/-}$ colon carcinoma. Science 275: 1784-1787. doi:10.1126/sci ence.275.5307.1784

Kuwabara T, Hsieh J, Muotri A, Yeo G, Warashina M, Lie DC, Moore L, Nakashima K, Asashima M, Gage FH. 2009. Wntmediated activation of NeuroD1 and retro-elements during adult neurogenesis. Nat Neurosci 12: 1097-1105. doi:10 $.1038 / \mathrm{nn} .2360$

Lan X, Jörg DJ, Cavalli FMG, Richards LM, Nguyen LV, Vanner RJ, Guilhamon P, Lee L, Kushida MM, Pellacani D, et al. 2017. Fate mapping of human glioblastoma reveals an invariant stem cell hierarchy. Nature 549: 227-232. doi:10.1038/ nature23666

Liao Y, Smyth GK, Shi W. 2014. featureCounts: an efficient general purpose program for assigning sequence reads to genomic features. Bioinformatics 30: 923-930. doi:10.1093/bioinfor matics/btt656

Lie D-C, Colamarino SA, Song H-J, Désiré L, Mira H, Consiglio A, Lein ES, Jessberger S, Lansford H, Dearie AR, et al. 2005. Wnt signalling regulates adult hippocampal neurogenesis. Nature 437: 1370-1375. doi:10.1038/nature04108

Lui TT, Lacroix C, Ahmed SM, Goldenberg SJ, Leach CA, Daulat AM, Angers S. 2011. The ubiquitin-specific protease USP34 regulates axin stability and $\mathrm{Wnt} / \beta$-catenin signaling. $\mathrm{Mol}$ Cell Biol 31: 2053-2065. doi:10.1128/MCB.01094-10

McCarthy DJ, Chen Y, Smyth GK. 2012. Differential expression analysis of multifactor RNA-seq experiments with respect to biological variation. Nucleic Acids Res 40: 4288-4297. doi:10.1093/nar/gks042

Moore KA, Lemischka IR. 2006. Stem cells and their niches. Science 311: 1880-1885. doi:10.1126/science.1110542

Mootha VK, Lindgren CM, Eriksson KF, Subramanian A, Sihag S, Lehar J, Puigserver P, Carlsson E, Ridderstråle M, Laurila E, et al. 2003. PGC-1 $\alpha$-responsive genes involved in oxidative phosphorylation are coordinately downregulated in human diabetes. Nat Genet 34: 267-273.

Munji RN, Choe Y, Li G, Siegenthaler JA, Pleasure SJ. 2011. Wnt signaling regulates neuronal differentiation of cortical intermediate progenitors. J Neurosci 31: 1676-1687. doi:10.1523/ JNEUROSCI.5404-10.2011

Nguyen LV, Vanner R, Dirks P, Eaves CJ. 2012. Cancer stem cells: an evolving concept. Nat Rev Cancer 12: 133-143. doi:10 $.1038 / \mathrm{nrc} 3184$

Park NI, Guilhamon P, Desai K, McAdam RF, Langille E, O'Connor M, Lan X, Whetstone H, Coutinho FJ, Vanner RJ, et al. 2017. ASCL1 reorganizes chromatin to direct neuronal fate and suppress tumorigenicity of glioblastoma stem cells. Cell Stem Cell 21: 411. doi:10.1016/j.stem.2017.08.008

Patel AP, Tirosh I, Trombetta JJ, Shalek AK, Gillespie SM, Wakimoto H, Cahill DP, Nahed BV, Curry WT, Martuza RL, et al. 2014. Single-cell RNA-seq highlights intratumoral heterogeneity in primary glioblastoma. Science 344: 1396-1401. doi:10.1126/science.1254257

Pollard SM, Yoshikawa K, Clarke ID, Danovi D, Stricker S, Russell R, Bayani J, Head R, Lee M, Bernstein M, et al. 2009. Glioma stem cell lines expanded in adherent culture have tumor-specific phenotypes and are suitable for chemical and genetic screens. Cell Stem Cell 4: 568-580. doi:10.1016/j.stem .2009.03.014

Reya T, Clevers H. 2005. Wnt signalling in stem cells and cancer. Nature 434: 843-850. doi:10.1038/nature03319

Rheinbay E, Suvà ML, Gillespie SM, Wakimoto $\mathrm{H}$, Patel $\mathrm{AP}$, Shahid M, Oksuz O, Rabkin SD, Martuza RL, Rivera MN, et al. 2013. An aberrant transcription factor network essential for Wnt signaling and stem cell maintenance in glioblastoma. Cell Rep 3: 1567-1579. doi:10.1016/j.celrep.2013.04 .021

Robinson MD, McCarthy DJ, Smyth GK. 2010. edgeR: a Bioconductor package for differential expression analysis of digital gene expression data. Bioinformatics 26: 139-140. doi:10 .1093/bioinformatics/btp616

Singh SK, Hawkins C, Clarke ID, Squire JA, Bayani J, Hide T, Henkelman RM, Cusimano MD, Dirks PB. 2004. Identification of human brain tumour initiating cells. Nature 432: 396-401. doi:10.1038/nature03128

Son MJ, Woolard K, Nam D-H, Lee J, Fine HA. 2009. SSEA-1 is an enrichment marker for tumor-initiating cells in human glioblastoma. Cell Stem Cell 4: 440-452. doi:10.1016/j.stem .2009.03.003

Steinhart Z, Angers S. 2018. Wnt signaling in development and tissue homeostasis. Development 145: dev146589. doi:10 $.1242 /$ dev.146589

Subramanian A, Tamayo P, Mootha VK, Mukherjee S, Ebert BL, Gillette MA, Paulovich A, Pomeroy SL, Golub TR, Lander ES, et al. 2005. Gene set enrichment analysis: a knowledgebased approach for interpreting genome-wide expression profiles. Proc Natl Acad Sci 102: 15545-15550.

Takebe N, Miele L, Harris PJ, Jeong W, Bando H, Kahn M, Yang SX, Ivy SP. 2015. Targeting Notch, Hedgehog, and Wnt pathways in cancer stem cells: clinical update. Nat Rev Clin Oncol 12: 445-464. doi:10.1038/nrclinonc.2015.61 
Rajakulendran et al.

Tirosh I, Venteicher AS, Hebert C, Escalante LE, Patel AP, Yizhak K, Fisher JM, Rodman C, Mount C, Filbin MG, et al. 2016. Singlecell RNA-seq supports a developmental hierarchy in human oligodendroglioma. Nature 539:309-313.doi:10.1038/nature20123

Vacik T, Lemke G. 2011. Dominant-negative isoforms of Tcf/Lef proteins in development and disease. Cell Cycle 10: 41994200. doi:10.4161/cc.10.24.18465

Zhang N, Wei P, Gong A, Chiu W-T, Lee H-T, Colman H, Huang $\mathrm{H}$, Xue J, Liu M, Wang Y, et al. 2011. FoxM1 promotes $\beta$-catenin nuclear localization and controls Wnt target-gene expres- sion and glioma tumorigenesis. Cancer Cell 20: 427-442. doi:10.1016/j.ccr.2011.08.016

Zheng H, Ying H, Wiedemeyer R, Yan H, Quayle SN, Ivanova EV, Paik JH, Zhang H, Xiao Y, Perry SR, et al. 2010. PLAGL2 regulates Wnt signaling to impede differentiation in neural stem cells and gliomas. Cancer Cell 17: 497-509. doi:10.1016/j.ccr .2010.03.020

Zurawel RH, Chiappa SA, Allen C, Raffel C. 1998. Sporadic medulloblastomas contain oncogenic $\beta$-catenin mutations. Cancer Res 58: 896-899. 


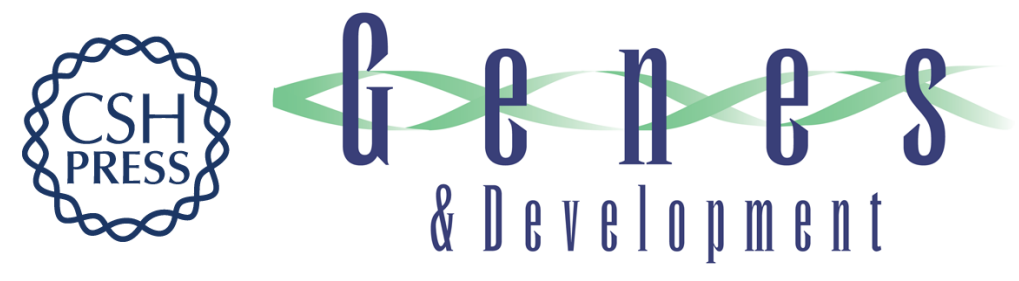

\section{Wnt and Notch signaling govern self-renewal and differentiation in a subset of human glioblastoma stem cells}

Nishani Rajakulendran, Katherine J. Rowland, Hayden J. Selvadurai, et al.

Genes Dev. 2019, 33: originally published online March 6, 2019

Access the most recent version at doi:10.1101/gad.321968.118

\section{Supplemental http://genesdev.cshlp.org/content/suppl/2019/03/06/gad.321968.118.DC1 Material}

References This article cites 47 articles, 15 of which can be accessed free at: http://genesdev.cshlp.org/content/33/9-10/498.full.html\#ref-list-1

Creative This article is distributed exclusively by Cold Spring Harbor Laboratory Press for the first Commons six months after the full-issue publication date (see

License http://genesdev.cshlp.org/site/misc/terms.xhtml). After six months, it is available under a Creative Commons License (Attribution-NonCommercial 4.0 International), as described at http://creativecommons.org/licenses/by-nc/4.0/.

Email Alerting Receive free email alerts when new articles cite this article - sign up in the box at the top Service right corner of the article or click here.

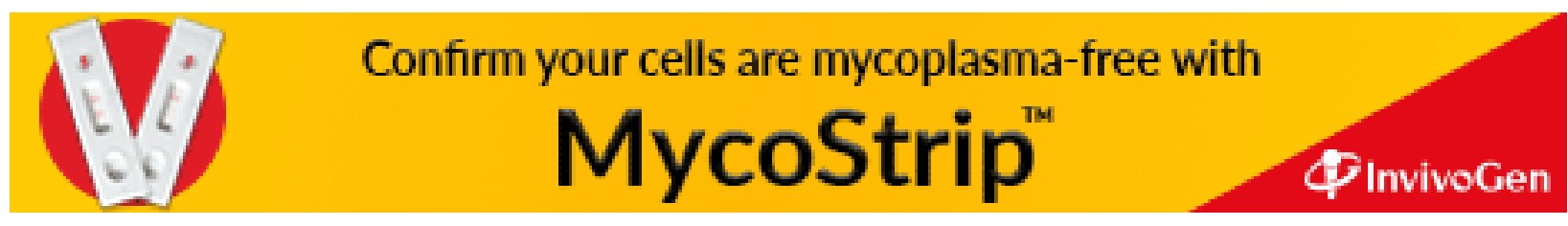

